\title{
MEDIA IKLAN MENGGUNAKAN APLIKASI ADOBE AFTER EFFEK GUNA PENUNJANG INFORMASI DAN PROMOSI DI CV. YUKA PRODUCTION KOTA TANGERANG
}

\author{
Riswanto $^{1}$ \\ Asti Ideliana ${ }^{2}$ \\ Siti Kholipah $\mathrm{M}^{3}$ \\ STMIK Raharja Jurusan Teknik Informatika ${ }^{1,2,3}$ \\ Jl. Jendral Sudirman No 40 Modern Cikokol Tangerang ${ }^{1,2,3}$ \\ Email:riswanto@raharja.info ${ }^{1)}$, asti@raharja.info ${ }^{2)}, \underline{\text { siti.kholipah@ @raharja.info }{ }^{3)}}$
}

\begin{abstract}
ABSTRAK
Perkembangan teknologi komputer khususnya bidang multimedia, audio visual dan broadcasting sudah sangat berkembang pesat saat ini serta semakin luasnya kebutuhan akan informasi pada masyarakat, maka semakin banyak kontribusi baru dalam menyajikan iklan baik sebagai media informasi maupun sebagai media promosi. CV. Yuka Production. bergerak di bidang Weeding Organizer dan Jasa Burning, berkontribusi untuk video shooting dan video grafer, merupakan perusahaan yang berpengalaman dalam bidang multimedia dan menjadi salah satu perusahaan besar di tangerang. Dengan tujuan untuk memperkenalkan identitas dan keseluruhan informasi yang terkait didalamnya. Akurat dan menarik dari segi tampilan maupun isi konten didalamnya. Iklan Adalah Segala bentuk pesan tentang suatu produk disampaikan melalui suatumedia, dibiayai oleh pemrakarsa yang dikenal, serta ditujukan kepada sebagian atauseluruh masyarakat.Penyajian informasi yang dikemas dalam bentuk video iklan dirasa sangat berguna untuk tujuan tersebut. Diharapkan video iklan ini bermanfaat dan bisa diimplementasikan oleh CV. Yuka Production.
\end{abstract}

Kata Kunci: Kata kunci : Video iklan, multimedia, informasi, promosi.

\begin{abstract}
The development of computer technology in particular fields of multimedia, visual and audio broadcasting already very rapidly growing at this time as well as the extent of the need for information on the society, the more recent contributions in serving as both a media information advertising and media promotion. Cv. Yuka Production. moves in the field; the service Organizer and Burning, contributing to video shooting and video grafer, is an experienced company in the field of multimedia and became one of the major companies in tangerang. With the aim to introduce the identity and overall information associated therein. Accurate and compelling in terms of the look or content therein. Advertising is any form of message about a product delivered via suatumedia, financed by the proponent are known, as well as addressed to the most atauseluruh of the community. The presentation of the information is packaged in the form of video ads prove very useful for the purpose. Video ads expected this beneficial and could be implemented by CV. Yuka Production.
\end{abstract}

Keywords: Keywords: Video advertising, multimedia, information, promotion.

\section{PENDAHULUAN}

Iklan adalah bagian dari media promosi yang merupakan salah satu bentuk sarana komunikasi antara perusahaan dengan konsumen.Melalui iklan perusahaan dapat memperkenalkan produk atau jasa kepada masyarakat luas baik melalui internet atau media elektronik lainnya,sehingga masyarakat sadar akan produk atau jasa baru yang ada dipasaran.Perusahaan berharap melalui iklan dapat meningkatkan penjualan produk atau jasa. Dalam melakukan pengiklanan ada beberapa media yang dapat dipergunakan.Media tersebut 
antara lain media cetak atau elektronik.Media iklan cetak berupa surat kabar,brosur,majalah,dan lain-lain.Sedangkan media elektronik berupa televisi,internet,dan radio. Seiring kemajuan zaman maka semakin tinggi pula persaingan antar perusahaan.Hal ini secara tidak langsung membuat perusahaan harus pandai dalam memilih media yang digunakan untuk mempromosikan produk atau jasa mereka,karena setiap media memiliki kekurangan dan kelebihan masing-masing.Pada umumnya banyak perusahaan yang memilih media elektronik khusunya televisi dan radio.Perusahaan-perusahaan tersebut menganggap bahwa iklan melalui televisi dan radio memiliki jangkauan yang luas dan lebih efektif.Selain itu iklan melalui media ini dianggap lebih menarik karena menampilkan audio dan visual. Disinilah penulis melihat bahwa media iklan dengan video sangat berperan untuk menarik perhatian seseorang dan adanya peluang untuk menunjukan kepada Calon Konsumen akan kinerja dan visual yang menarik yang telah CV. Yuka Production berikan. Dalam perancangan media iklan ini penulis memanfaatkan special effect dalam membuat media iklan video yang singkat berdurasi 2 menit. Penulis akan mengaplikasikan video iklan ini pada web dan meng-upload-nya ke youtubedan CD/DVD, agar calon konsumen lebih mudah untuk melihat keunggulan-keunggulan yang ditawarkan.

\section{RUMUSAN MASALAH}

CV. Yuka Production adalah sebuah perusahaan wedding organizer dan Jasa Burning yang memasarkan sebuah produk jasa. Tetapi pada saat ini CV. Yuka Production hanya memiliki promosi melalui web atau internet sehingga kurang efektif untuk mempromosikan kepada masyarakat terutama calon customer, saya berencana membuat video iklan dengan menggunakan sofwear adobe Photoshop dan after efek yang hasilnya seperti video iklan, video iklan yang saya buat akan menampilkan cara pembuatan dari bahan mentahan menjadi jadi, hasil video tersebut dan akan di uploud melalui youtube, sosial media sehingga pemasaran dari CV. Yuka Production lebih meluas lagi.

\section{LANDASAN TEORI Konsep Dasar Media}

"Media adalah sarana untuk menyampaikan pesan atau informasi kepada public dengan menggunakan berbagai unsur komunikasi grafis seperti teks atau gambar atau foto 5 ."Media adalah segala bentuk yang digunakan untuk menyalurkan informasi. Pengertian media yang diberikan AECT (Association for Education Communication and Technology) ini menunjukkan bahwa istilah "media" memiliki makna yang sangat umum, ini disebabkan kata "segala bentuk" yang terdapat dalam pengertian tersebut memberikan makna bahwa yang disebut media tidak terbatas pada satu jenis media tertentu. Berdasarkan pendapat-pendapat yang dikemukakan di atas maka penulis dapat memberikan kesimpulan bahwa media adalah sarana yang digunakan untuk menyampaikan informasi dan kegiatan promosi ${ }^{3}$.

\section{Konsep Dasar Iklan Pengertian Iklan}

Iklan sering disebut dengan istilah berbeda-beda. Masyarakat Amerika dan Inggris, menyebutnya sebagai advertising. Istilah ini berasal dari bahasa latin yaitu ad-vere yang berarti mengoperkan pikiran dan gagasan kepada pihak lain. Di Perancis disebut dengan reclamare yang berarti meneriakan sesuatu secara berulang-ulang ${ }^{13}$. "Iklan merupakan salah satu bentuk komunikasi yang bertujuan untuk mempersuasi para pendengar, pemirsa, dan pembaca agar mereka memutuskan untuk melakukan tindakan tertentu", 
Dari beberapa definisi iklan diatas, dapat disimpulkan bahwa maksud dan tujuan dari iklan adalah untuk menarik perhatian guna mempengaruhi orang lain.

\section{Fungsi Iklan}

a. Media Komunikasi

Artinya, bahwa iklan mampu menjadi sarana penyampai pesan dari produsen, yaitu pihak penghasil produk (yang bertindak sebagai komunikator) kepada konsumennya (yang bertindak sebagai khalayak penerima pesan, komunikan atau audience-nya).

b. Media Pendidikan

Selain mampu sebagai sarana komunikasi dari produsen ke konsumen, fungsi lain dari iklan adalah iklan mampu digunakan oleh komunikator untuk mengajarkan nilai-nilai tertentu sebagaimana dikehendaki komunikator.

c. Fungsi Ekonomi

Dengan iklan, ekonomi dapat berjalan dengan cepat, karena iklan dapat mendorong percepatan konsumsi. Sebaliknya, tanpa iklan ekonomi kemungkinan akan melambat, bahkan macet dan berhenti bergerak.

d. Fungsi Sosial

Fungsi ini membawa dua makna penting, yaitu: Pertama, iklan sebagai alat untuk saling berkomunikasi (sebagai penghubung) antara seseorang dengan orang lainnya. Kedua, sebagai alat penyampai pesan-pesan sosial. Fungsi penyampai pesan sosial ini disadari atau tidak, banyak terlihat dalam kehidupan masyarakat. Melalui iklan, masyarakat dapat tergerak memberikan bantuan kemanusiaan seperti misalnya bantuan bencana banjir ${ }^{12}$.

\section{Unsur-unsur Iklan}

Unsur iklan dibagi menjadi lima, yaitu:

1. Attention (perhatian)

Iklan yang baik harus dapat menarik perhatian khalayak umum.

2. Interest (minat)

Setelah mendapat perhatian maka harus ditingkatkan menjadi minat sehingga timbul rasa ingin tahu secara rinci dalam diri konsumen.

3. Desire (keinginan)

Suatu cara untuk menggerakkan keinginan suatu konsumen.

4. Conviction (rasa percaya)

Untuk mendapat rasa percaya dalam diri konsumen maka sebuah iklan harus ditunjang berbagai kegiatan peragaan seperti pembuktian atau sebuah kata-kata.

5. Action (tindakan)

Tindakan merupakan tujuan akhir dari produsen untuk menarik konsumen agar membeli atau menggunakan produk dan jasanya ${ }^{12}$.

\section{Standar dan Format Video}

Standar sistem penyiaran di seluruh dunia terbagi menjadi 3 kelompok diantaranya NTSC (National Television System Comitte), PAL (Phase Alternating Line), SECAM (Sequential Colour Avec Memory) ${ }^{1}$. 


\section{Konsep Dasar Video Profile}

Company Profile adalah sebuah aset suatu lembaga atau perusahaan yang dapat digunakan untuk meningkatkan suatu image atau citra dari perusahaan untuk menjalin kerjasama dengan relasi perusahaan, lembaga dan instansi yang terkait lainnya ${ }^{4}$.

\section{Konsep Dasar Promosi}

Promosi adalah media untuk mengenalkan suatu produk barang dan jasa yang baru atau memperkuat brandimage suatu produk yang telah ada sebelumnya ${ }^{16}$.

\section{Bentuk Promosi}

1. Advertising atau Iklan.

Iklan merupakan salah satu bentuk promosi yang dapat dengan cepat meluas dan meraih target konsumen mereka namun dalam pelaksanaannya, memerlukan dana yang besar.

2. Personal Selling atau Penjualan Personal.

Dikatakan bahwa Personal penjualan Personal merupakan alat paling efektif pada tahap tertentu dalam proses keputusan pembelian, terutama dalam menentukan pembelian, keyakinan dan tindakan yang akan diputuskan.

3. Sales Promotion atau Promosi Penjualan.

Promosi penjualan sering kali tidak terlalu efektif dibandingkan dengan iklan dana penjualan Personal dalam membangun preferensi merek jangka panjang dan hubungan pelanggan.

4. Public Relation atau Hubungan Pelanggan.

Hubungan pelanggan dipercaya dalam hal sponsorship, pembuatan event dan cerita baru dalam perusahaan karena terlihat lebih nyata untuk para konsumen atau pembaca dibanding dengan iklan.

5. Direct Marketing atau Pemasaran Langsung.

Banyak bentuk yang digunakan dalam pemasaran langsung sesuai dengan kebutuhan atau karakteristik setiap perusahaan dan bidang yang digeluti, seperti email langsung, katalog, tele-Marketing, online-Marketing dan sebagainya ${ }^{6}$.

\section{Konsep Dasar Informasi}

Informasi adalah data yang telah diolah menjadi sebuah bentuk yang lebih berarti bagi penerimanya, dan bermanfaat dalam mengambil sebuah keputusan ${ }^{4}$.

\section{Jenis-jenis Informasi}

1. Informasi Penyejuk

Informasi keadaan sekarang yang merangkum keadaan umum bisnis atau organisasi.

2. Peringatan

Berisi penunjuk terhadap sesuatu yang tidak biasa atau barangkali memerlukan tindakan manajerial atau perubahan-perubahan rencana.

3. Indikator Kunci

Berisi ukuran aspek-aspek penting yang berkaitan dengan kinerja organisasi.

4. Informasi Situasional

Informasi terkini tentang proyek, masalah, atau isu penting yang memerlukan perhatian manager.

5. Gosip

Informasi informal yang berasal dari sumber seperti pihak industri yang terkadang berguna untuk menangani suatu masalah.

6. Informasi eksternal 
Informasi yang berasal dari luar departemen atau perusahaan. Kadangkala informasi ini masih hangat dan berjangka pendek (misalnya adanya penandatanganan kontrak oleh pesaing), tetap kadangkala berjangka panjang (misalnya studi lingkungan yang dilakukan lima tahun terakhir) ${ }^{10}$.

\section{Pengertian Promosi}

Promosi adalah tindakan menginformasikan atau meningkatkan konsumen tentang spesifikasi produk atau merek. Promosi mempunyai kekuatan untuk menyampaikan pesan, dan diperlukan perancangan khusus agar promosi tersebut memiliki visual yang kuat dan menciptakan keserasian didalam rangkaian pemasaran, karena promosi adalah berkaitan langsung dalam upaya untuk memperkenalkan produk kepada konsumen dengan memikat hati mereka melalui pemberian kesan-kesan baik, yang mampu diingat dan dirasakan oleh konsumen $^{2}$.

\section{Tujuan Promosi}

Tujuan utama dari promosi adalah menginformasikan, mempengaruhi, dan membujuk serta mengingatkan pelanggan sasaran tentang perusahaan dan bauran pemasaran ${ }^{15}$.

\section{Program Aplikasi Penunjang Video Profile Adobe Photoshop CS6}

Adobe Photoshop CS2 adalah suatu perangkat lunak canggih yang dapat Anda gunakan untuk membuat, menyunting dan memanipulasi tampilan termasuk mengoreksi warna dan memberi efek tampilan atas sebuah gambar atau photo, hasil dari program ini merupakan sebuah gambar / image, di dalam komputer grafis terbagi menjadi 2 kelompok yaitu gambar Bitmap dan gambar Vektor ${ }^{17}$.

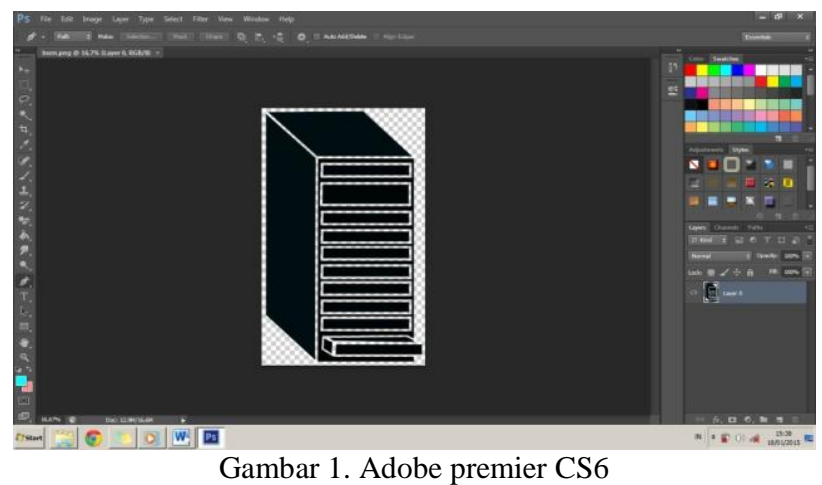

\section{Adobe After Effect}

Adobe After Effect merupakan software motion graphics yang dapat digunakan sebagai software compositing, animasi dan video effect ${ }^{8}$.

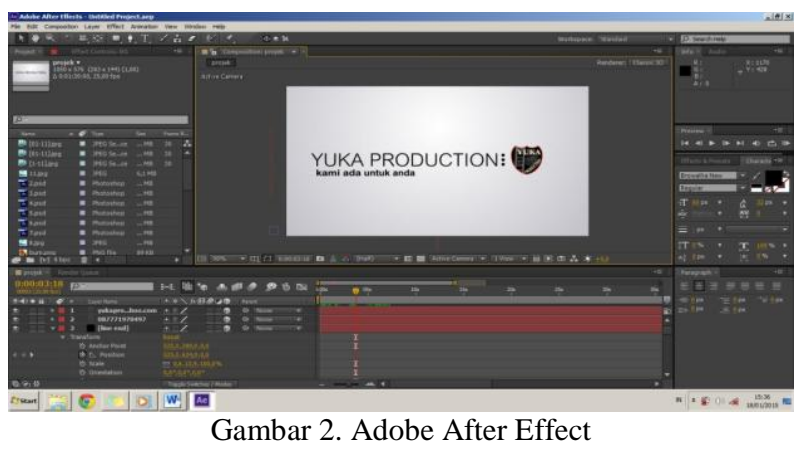




\section{Tahapan Produksi}

\section{Pra Produksi}

Pra produksi adalah sebuah proses produksi yang merupakan tahapan awal dari seluruh kegiatan yang akan datang atau juga disebut sebagai tahapan perencanaan ${ }^{13}$.

\section{Konsep Dasar Multimedia Audio Visual and Broadcasting Pengertian Multimedia}

Multimedia adalah penggunaan komputer untuk menyajikan dan menggabungkan teks, suara, gambar, animasi dan video dengan alat bantu (tool) dan koneksi (link) sehingga pengguna dapat melakukan navigasi, berinteraksi, berkarya dan berkomunikasi. Multimedia sering digunakan dalam dunia hiburan. Selain dari dunia hiburan, Multimedia juga dimanfaatkan dalam dunia pendidikan dan bisnis ${ }^{11}$.

\section{Pengertian Audio Visual}

Audio visual merupakan gabungan dari dua kata yaitu audio yang berarti suara dan visual yang berarti gambar, atau dengan kata lain menjelaskan, "Audio Visual adalah alat peraga yang dapat dilihat dan didengar dalam hal ini gambar yang bergerak menimbulkan suara ${ }^{3} . "$

Sehingga dapat ditarik kesimpulan bahwa audio visual merupakan unsur yang dimiliki oleh televisi berupa suara dan gambar, baik gambar bergerak maupun gambar mati atau still picture, sehingga menghasilkan suatu pesan yang dapat dimengerti oleh khalayak.

\section{Pengertian Sinopsis}

Sinopsis adalah ringkasan cerita media periklanan atau film, merupakan bentuk atau pendekatan dari sebuah periklanan atau film dengan tetap memperhatikan unsur-unsur pencerminan dari sebuah periklanan atau film tersebut ${ }^{5}$.

\section{Pengertian Storyboard}

Story Board adalah rangkaian gambar ilustrasi yang berusaha menjelaskan bahasa tulisan scenario kedalam bahasa visual ${ }^{9}$.

Story Board adalah rancangan berupa sket gambar yang dilengkapi dengan petunjuk atau catatan pengambilan gambar untuk kebutuhan shooting ${ }^{5}$.

\section{Pengertian Broadcasting}

Broadcasting adalah kegiatandalam cara menyampaikan pesan, ide, hasrat, kepada khalayak dengan menggunakan fasilitas frequency, dengan kata lain dunia broadcasting adalah merupakan suatu kegiatan penyiaran yang dilakukan oleh seorang penyiar ${ }^{1}$.

\section{LITERATURE REVIEW}

1. Perancangan Video Iklan 3d Motion Graphic sebagai Media Promosi Elmer, 2015, Surakarta, adalah salah satu judul Skripsi yang di buat oleh Wahyu Kristianto, selaku mahasiwa Universitas Sebelas Maret. Penelitian ini menjelasan tentang Pembuatan video iklan menggunakan3d motion graphic.

2. Implementasi Animasi 3d Sebagai Iklan Televisi Pupz Miracle Yogyakarta Studi Pergerakan Kain 2013, adalah salah satu judul Jurnal yang dibuat oleh I Made Aprilian Aditya, Amir Fatah Sofyan selaku mahasiswa Stmik Amikom Yogyakarta. Penelitian ini menjelaskan tentang pembuatan video animasi iklan televise pupz miracle.

3. Perencanaan Dan Pembuatan Iklan Dengan Media Film Kartun 2d (Dua Dimensi) Untuk Pt.Inoarsitas, 2013, Yogyakarta, adalah salah satu judul Jurnal yang dibuat oleh Yoga 
Pasramakrisnan, Hanif Al Fatta selaku mahasiswa Stmik Amikom Yogyakarta. Penelitian ini menjelaskan tentang pembuatan iklan dengan media film kartun.

4. Analisis Dan Perancangan Video Iklan Pada Hotel Duta Garden Yogyakarta Sebagai Media Promosi, 2013, Yogyakarta, adalah salah satu judul Jurnal yang dibuat oleh Yanu Rahinda, Dhani Aritmanto, Selaku mahasiswa Stmik Amikom Yogyakarta. Penelitian ini menjelaskan tentang pembuatan video iklan pada hotel duta garden Yogyakarta.

5. Media Promosi Iklan Bakpia Pathok 25 Yogyakarta Menggunakan Penggabungan Live Shooting Dan Teknologi 3d, 2013, Yogyakarta, adalah salah satu judul Jurnal yang dibuat oleh Haris Yuliantoro, Amir Fatah Sofyan selaku mahasiswa Stmik Amikom Yogyakarta. Penelitian ini menjelaskan tentang pembuatan iklan bakpia pathok 25 yogyakarta

\section{METODE PENELITIAN}

Agar perolehan data lebih akurat dipenelitian ini, terdapat beberapa penerapan metode, yaitu : (1). Metode Analisa Permasalahan. Metode ini merupakan suatu metode yang digunakan untuk menentukan topik permasalahan penelitian, dalam hal ini dilakukan dengan bentuk interview yang menanyakan tentang permasalahan - permasalahan yang terdapat pada lembaga instansi yang terkait dengan proses mempromosikan perusahaan; (2). Metode Pengumpulan Data yaitu cara untuk mendapatkan data dengan jalan pengamatan secara langsung ke lokasi (Observasi), Interview ataupun dari kajian pustaka; (3).Analisa Data berupa pengolahan data atau informasi yang diangkat dari hasil perancangan dan penelitian terhadap video iklan CV. Yuka Production Tangerang yang akan dianalisa dan diolah menggunakan software atau aplikasi program yang mendukung dalam proses perancangan; (4).Metode Analisa Perancangan, dalam produksi Perancangan Video iklan Sebagai Media Promosi pada CV. Yuka Production tangerang dipergunakan aplikasi- aplikasi penunjang diantaranya aplikasi adobe Photoshop sebagai pengolah foto setelah dilakukan produksi, sedangkan aplikasi Adobe After Effects CS6 dipergunakan untuk pembuatan animasi bumper saat opening isi hingga closing; (5). Konsep Dasar Media berisi mengenai Preproduction, Production, dan Postproduction.

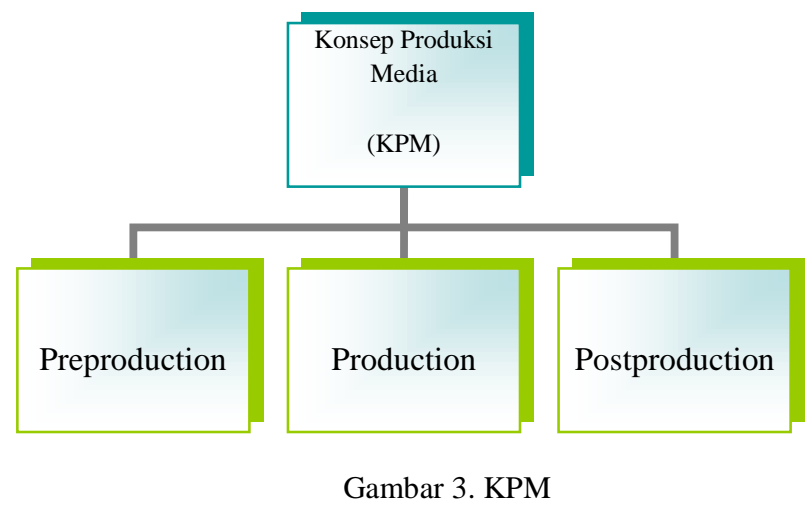

\section{Preproduction}

Untuk Preproduction adalah step atau langkah dimana dimulainya ide, perencanaan dan persiapan dari Konsep Produksi MAVIB. Ada tujuh langkah Preproduction dalam Konsep Produksi MAVIB, dimulai dari Ide yang dituangkan secara sistematis, lalu diikuti dengan pembuatan sinopsis, Script Writting dan Storyboard. 


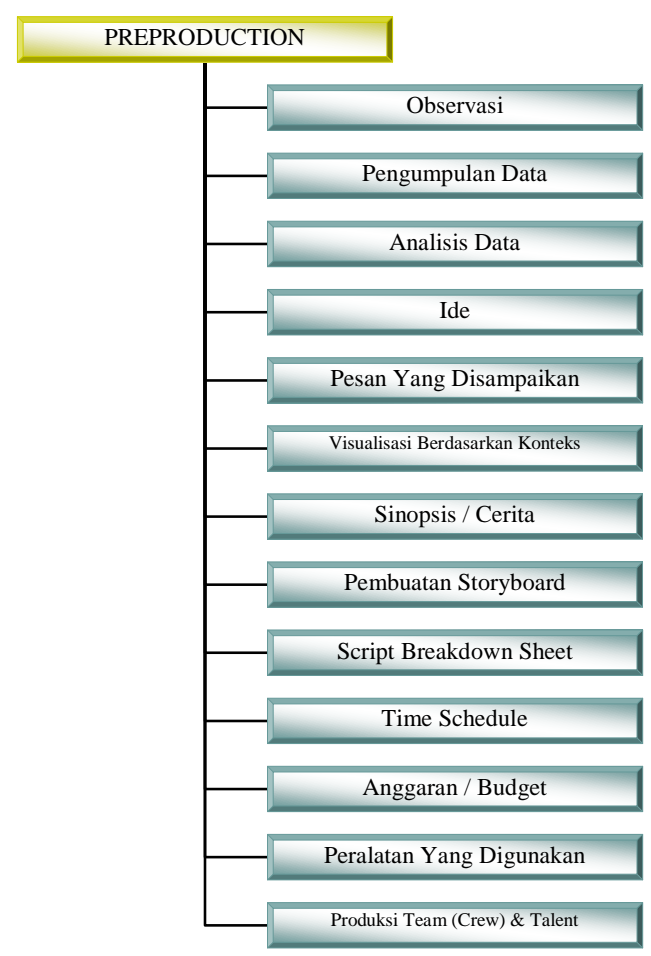

Gambar 4. Preproduction

\section{Layout Kasar}

Layout Kasar adalah gambar kerja untuk memperlihatkan komposisi tata letak naskah, gambar yang akan dibuat, biasanya pada layout kasar ini dibuat hitam putih dengan menggunakan coretan atau sketsa pensil gambar yang dibuatsecara manual.

\section{Scene 1}

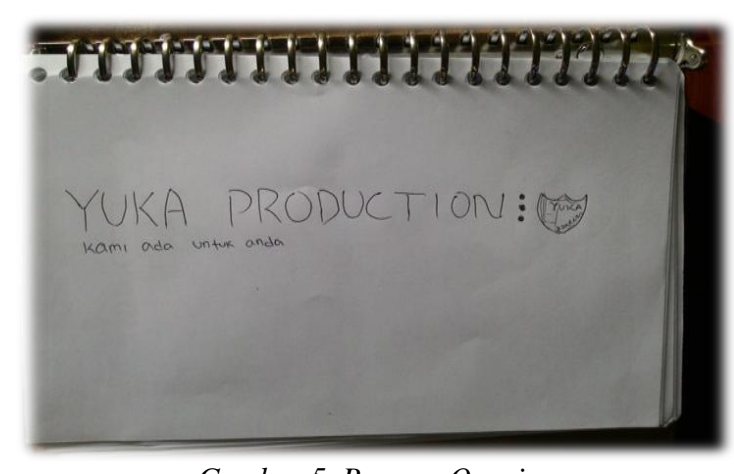

Gambar 5. Bumper Opening

\section{Scene 2}

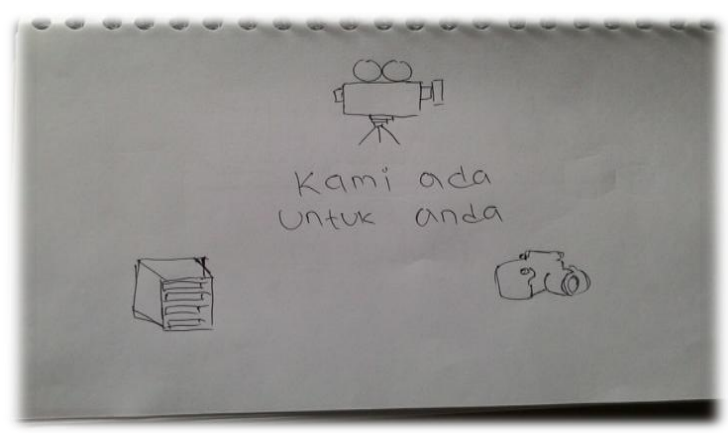

Gambar 6. Menampilkan video kami ada untuk anda 
Scene 3

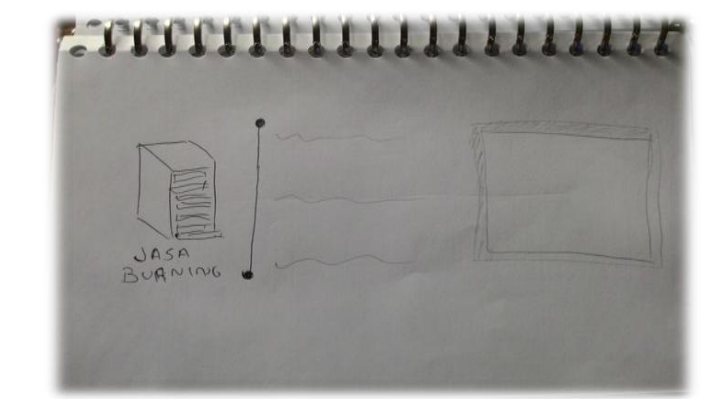

Gambar 7. Menampilkan video tentang produk jasa burning

Scene 4

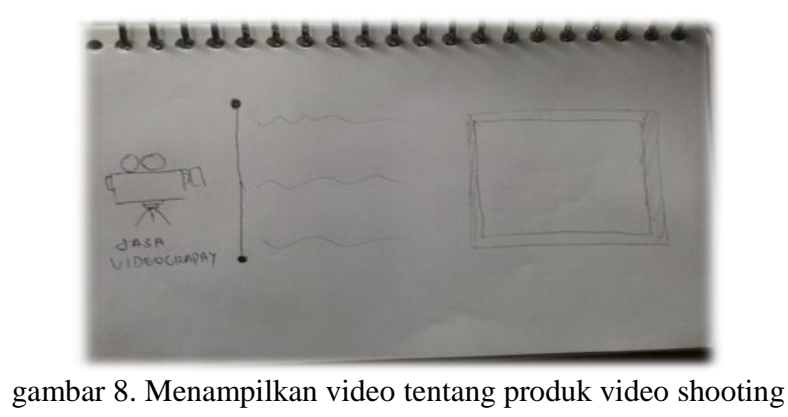

Scene 5

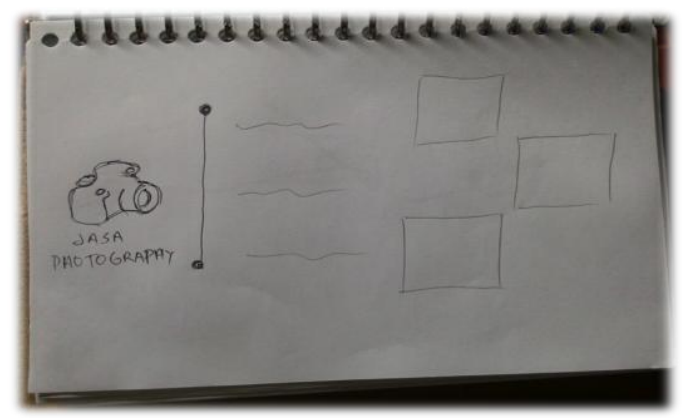

Gambar 9. Menampilkan video tentang fotography

\section{Storyboard}

Storyboard adalah rancangan berupa sket gambar yang dilengkapi dengan petunjuk atau catatan pengambilan gambar untuk kebutuhan shooting. Selama proses pra produksi, perencanaan yang berhubungan dengan visualiasasi yang akan dibuat membutuhkan Storyboard sebagai media bantuannya.

Scene 1

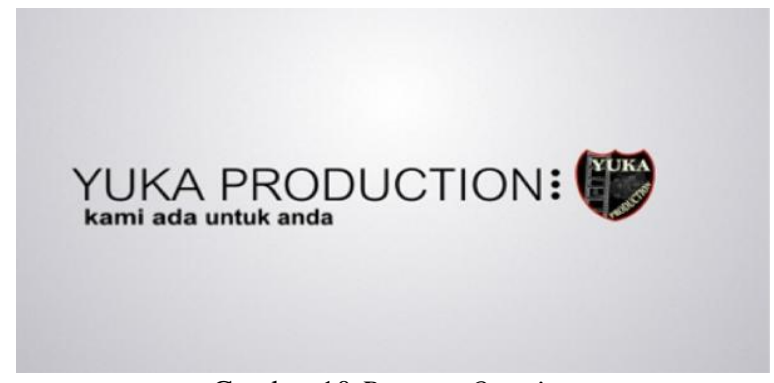

Gambar 10 Bumper Opening 
Scene 2

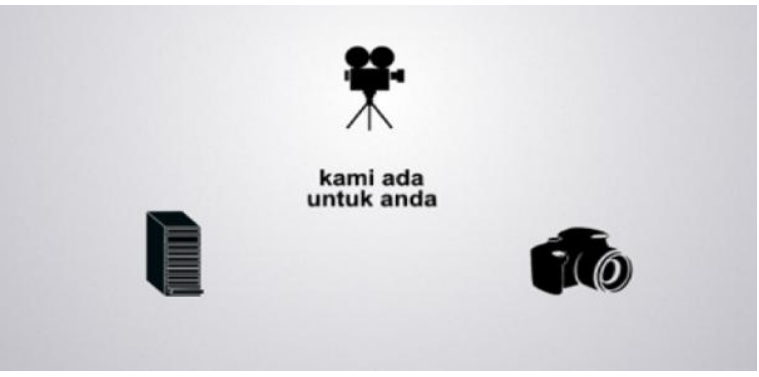

Gambar 11 Menampilkan video kami ada untuk anda

Scene 3

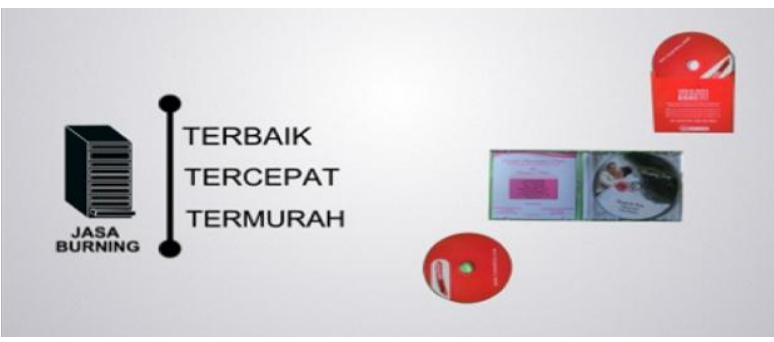

Gambar 12 Menampilkan video tentang produk jasa burning

Scene 4

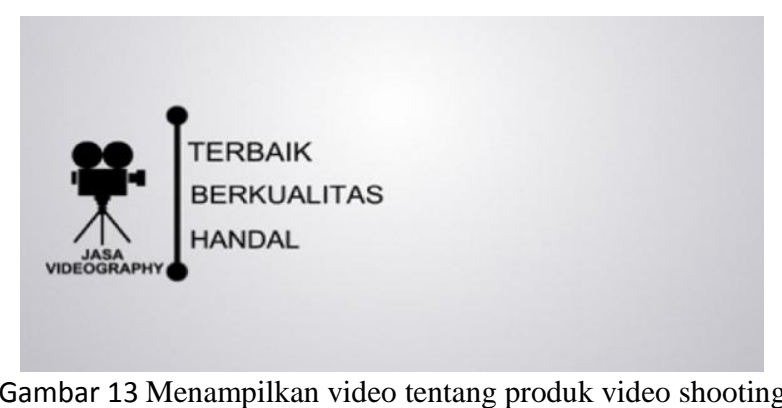

Scene 5

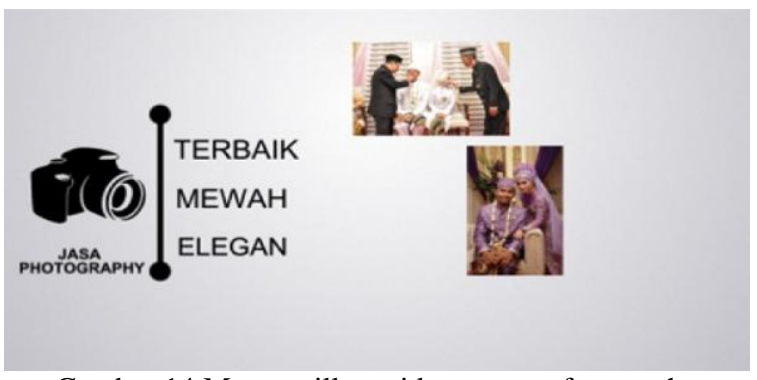

Gambar 14 Menampilkan video tentang fotography

Scene 6

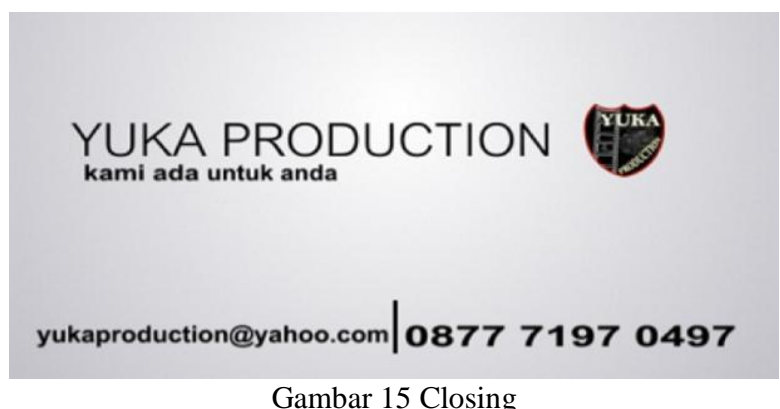

Gambar 15 Closing 


\section{Setting Alat}

Secara umumalat yang dibutuhkanadalahlaptop. Dalampembuatan video audio iklan. Dalam video audio visualinibanyakdigunakanlaptop untung pengeditan video iklan sedangkan pengambilan suara untuk wawancara menggunakan audiomicrofonshotgunyang dipasangkan pada kamera videoPanasonic MD10000.

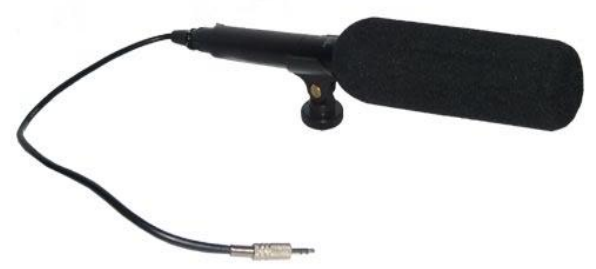

Gambar 16. microfon Shotgun

\section{Production}

Production adalah proses pengambilan gambar atau shooting video dengan bekerjasamanya antara pemain dan crew untuk pewujudan rumusan dari tahap preproduction dalam bentuk skenario, naskah, dan storyboard yang telah dibuat.

\section{Strategi Multimedia}

$\begin{array}{lll}\text { Geografi } & \text { : Jakarta Kota Tangerang } \\ \text { Demografi } & : \bullet \text { JenisKelamin } & \text { : Pria\&Wanita } \\ & \bullet \text { Usia } & \text { : Masyarakat Umum } \\ & \bullet \text { KelasEkonomi } & \text { : Menengah } \\ & \bullet \text { Sasaran } & \text { : Masyarakat umum }\end{array}$

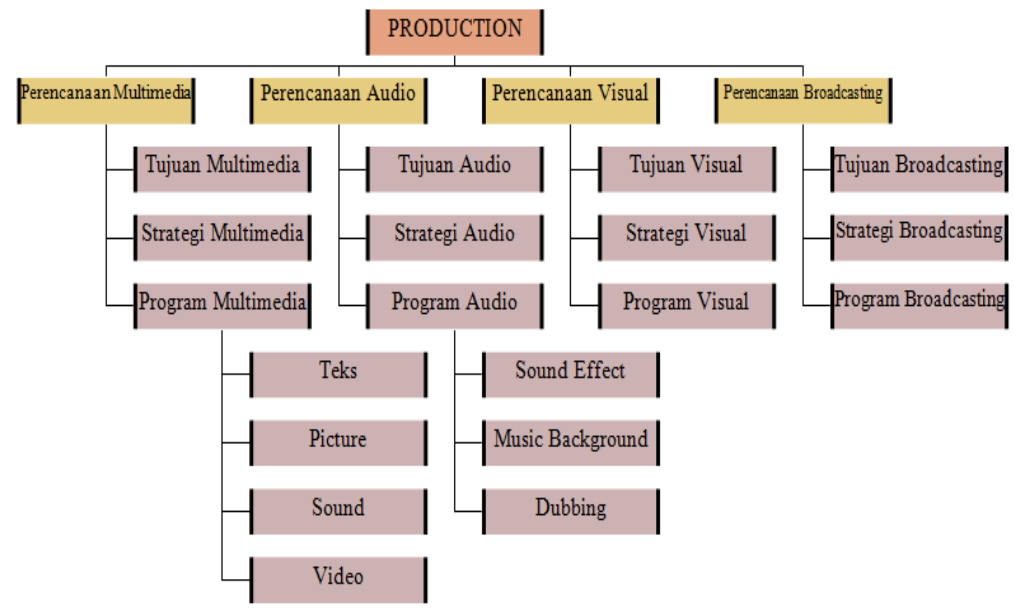

Gambar 17. Production

\section{Postproduction}

Tahap postproduction adalah proses finishing sebuah karya sampai menjadi sebuah video iklan yang utuh dan mampu menyampaikan sebuah cerita atau pesan kepada audience. Dalam proses postproduction semua gambar yang didapat pada proses production di satukan dan di edit oleh seorang editor. 


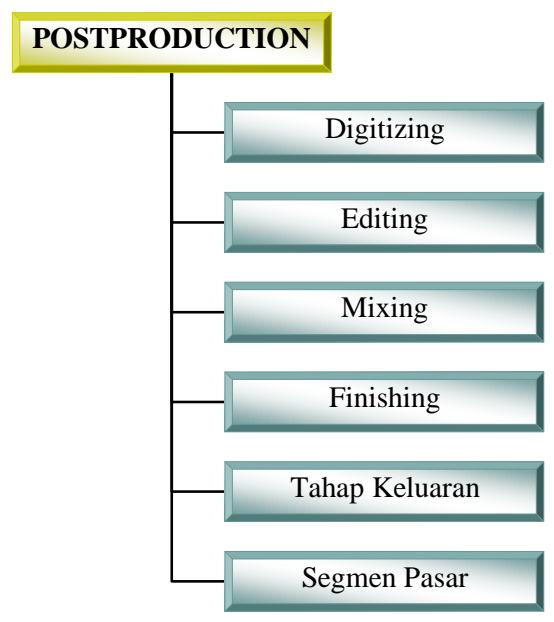

Gambar 18. Postproduction

\section{KESIMPULAN}

Setelah penulis melakukan penelitian pada CV. Yuka Production, penulis berkesimpulan bahwa Media video iklan perusahaan yang dikemas dalam bentuk video iklan sangat di perlukan bagi CV. Yuka Production khususnya di bidang wedding organizer dan jasa burning dengan adanya Media video iklan perusahaan tersebut dapat meningkatkan suatu image atau citra dari masyarakat agar tertarik dengan produk dari CV. Yuka Production.

Dalam pembuatan media video iklan yang baik, harus memperhatikan faktor-faktor yang berhubungan dengan CV. Yuka Production, mulai dari pembuatan gambar, tampilan video, isi pesan dan penutup. Hal ini bertujuan untuk memperkuat media video iklan dalam mempromosikan Produk weding organizer dan jasa burning untuk mengajak masyarakat dapat berlangganan dan menjadi pelanggan tetap dari CV. Yuka Production.

\section{DAFTAR PUSTAKA}

[1] Arifin, Eva. 2012. Broadcasting to be broadcaster. Yogyakarta : Graha Ilmu

[2] Arriesanti, Hani Dewi, Muhamad Yusup, Ceria Marcelia. 2014. Penerapan Multimedia Audio Galery Ilearning Community And Services (Magics) Sebagai Media Penyimpanan Dokumentasi Pada Perguruan Tinggi Raharja. Journal CCIT Vol. 7 No. 2 - Januari 2014. Tangerang : Perguruan Tinggi Raharja

[3] Atmohoetomo. 2011. Media Audio Visual Pendidikan dan Proses Produksi Programnya. Bandung : Alfabeta

[4] Binanto, Iwan,. 2010. Multimedia Digital (Dasar Teori dan Pengembangannya). Yogyakarta : Andi

[5] Desrianti, Dewi Immaniar, Untung Rahardja, Reni Mulyani. 2012. Audio Visual As One Of The Teaching Resources On Ilearning. Journal CCIT Vol.5 No.2-Januari 2012. Tangerang: Perguruan Tinggi Raharja

[6] Destrianti, Dewi Immaniar, Sudaryono, Dwi Ayu Ningrum. 2014. Enriching Media Merchandise Sarana Penunjang Promosi Studi Kasus Pada Bookstore. Journal CCIT Vol. 7 No.3 - Mei 2014. Tangerang : Perguruan Tinggi Raharja

[7] Guritno, Suryo, dkk. 2011.. Theory and Application of IT Research Metodologi Penelitian Teknologi Informasi. Yogyakarta: Andi. 
[8] Hasibuan, Zainal A. 2007. Metodologi Penelitian Pada Bidang Ilmu Komputer Dan Teknologi Informasi : Konsep, Teknik, Dan Aplikasi. Jakarta: Fakultas Ilmu Komputer Universitas Indonesia.

[9] Hendratman, Hendi, ST. 2010. Tips n Trix Computer Graphics Design. Bandung : Informatika

[10] Hendratman, Hendi, ST.2011. The Magic of Adobe After Effects. Bandung : Informatika

[11] Imanto, Teguh. 2012. Diklat Pasca Produksi Televisi.. Jakarta : Universitas Esa Unggul

[12] Kriyantono, Rachmat., S.Sos., M.Si.,2011.Teknik Praktis, Riset Komunikasi, Jakarta : Kencana

[13] Liliweri. 2011. Teknik Membuat Iklan. Jakarta : Indie

[14] Wibowo, Fred. 2012. Teknik Produksi Program Televisi. Yogyakarta : Pinus.

[15] Wibowo, Ibnu Teguh. 2013. Belajar Desain Grafis. Buku Pintar. Yogyakarta.

[16] Widada, Sugeng. 2012. Diktat Mata Kuliah Nirmana. Tangerang: Perguruan Tinggi Raharja.

[17] Widyatama, Rendra. 2011. Teknik Menulis Naskah Iklan. Yogyakarta : Cakrawala. 